\title{
Research on Responsive Design Strategy for Daylighting in Training Stadium in Guangzhou, China
}

\author{
Li Jin ${ }^{1, a}$,Cai Shenzhen², b \\ ${ }^{1}$ China, Guangdong, Canton, South China university of technology, State Key Laboratory of \\ Subtropical Building Science, 510640 \\ ${ }^{2}$ China, Guangdong, Canton, South China university of technology, State Key Laboratory of \\ Subtropical Building Science, 510640 \\ a liharbin@126.com, b yidieminnan@qq.com
}

\begin{abstract}
Keyword: Responsive design; dynamic sunshade component; parameterization design; Guangzhou, China
\end{abstract}

\begin{abstract}
In order to optimize indoor light environment and solar radiation level in training stadium in Guangzhou, China, parameterization building design method is employed in the research, and a sunshade system response design strategy for training stadium with light comfort applicable for sports population in the region is initially obtained. Firstly, by combining Radiance and Ecotect performance analysis software, Grasshopper parameterization program platform and genetic algorithm, optimized simulation analysis is made on indoor light environment and solar radiation level relating to sunshade components of training stadium in different seasons and in different periods. Furthermore, by analyzing the optimal scheme related data, we have initially obtained the function relationship controlling indoor illumination and solar radiation. Research results show that optimized dynamic sunshade system model can, in different seasons and periods, satisfy the demand of sports population in the local training stadium for comfortable lighting environment and provide better control of indoor solar radiation, and promote a healthy and comfortable indoor sports environment.
\end{abstract}

\section{Overview}

\section{Origin: National lighting design for training stadium}

Characterized by hot summer and warm winter, Guangzhou enjoys subtropical monsoon climate, abundant sunlight sources and strong solar radiation, with mean annual sunshine duration around $1,900 \mathrm{~h}$ and annual percentage of sunshine $40 \%-50 \%$. Sunshade and thermal insulation in summer is the primary concern of building design. Building shading design is one of the important design means to regulate and improve indoor lighting environment and outdoor solar radiation. Since training stadium has relatively large building spaces, irrational daylighting design will reduce the comfort of indoor light environment and increase lighting energy consumption; furthermore, as outdoor light environment keeps changing, the indoor light environment may be difficult to be controlled and stabilized within the acceptable range and for this reason, we focus on dynamic sunshade system, dynamically regulate indoor light environment and control solar radiation through responsive design of building shading system. 


\section{Research essence: optimize indoor light environment in training stadium and control indoor solar radiation}

Indoor light environment and solar radiation in building are two interplayed and interacted factors to indoor physical environment. This research intends to optimize indoor light environment and solar radiation by utilizing building sunshade system. Sunshade design, however, may decrease indoor daylight efficiency and when indoor daylighting efficiency is enhanced, shading efficiency may be reduced. Only when both technical means are well balanced can improve the comfort of indoor physical environment and energy saving efficiency in a building, and then indoor solar radiation will be properly controlled while indoor light environment is optimized.

\section{Optimization design of indoor sports light environment and solar radiation}

Indoor light environment and solar radiation in building are two interplayed and interacted factors to indoor physical environment, shall be simultaneously considered during optimization design. Based on comfort scope of sports light obtained from predecessors, optimized simulation analysis is made on indoor light environment and solar radiation level relating to sunshade components of training stadium in different seasons and in different periods through parametric design method, in order to ensure comfortable indoor light environment and solar radiation in training stadiums. Specific procedures of parametric design: parametric modeling, performance simulation analysis, automatic optimization, comprehensive analysis and conclusion. [1]

\section{Parametric modeling}

Used to compile modeling program, Grasshopper (a visual programming platform based on Rhinoceros) can adjust and control model parameters at real time, and provide platform for automatically revised model parameters during automatic optimization. [2] Generally the stadium site shall be multi-functionally laid out and, depending on the rules on the size of individual sport stadium site, the basic model is designed as $38 \mathrm{mx} 36 \mathrm{mx} 10 \mathrm{~m}$. The basic model is full-open at side face, On this basis, the training hall model for the joint lighting mode of roof and side interface is optimized, The specific space model is shown in Table2-1.

Table 2-1 Space model table

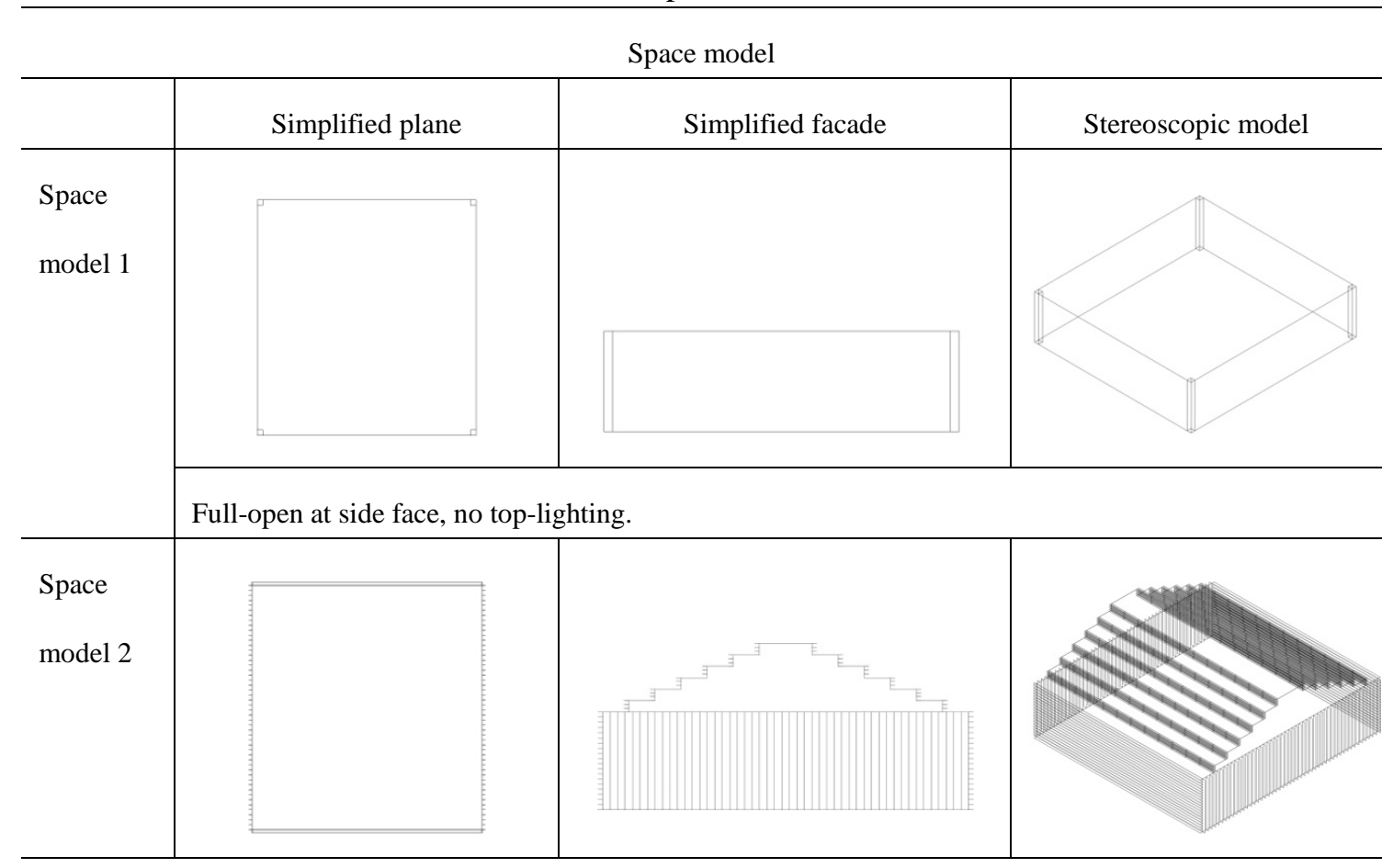




\section{Performance simulation analysis}

(1) After parametric modeling, it is converted into grid. By means of Honeybee and Ladybug (plug-in of Grasshopper), the model is imported into Radiance software (architectural daylight and lighting simulation software developed by Lawrence Berkeley National Laboratory in 1984, subordinate to United States Department of Energy) for daylight analysis. By means of GECO (plug-in of Grasshopper), the model is imported into software Autodesk. Ecotect Analysis (building environment performance analysis software jointly developed by UK architect Andrew Marshall and his wife) for solar radiation analysis. [3]

(2) Basis of setting simulation conditions

Based on climatic data from Guangzhou Weather Bureau over recent years, the solar radiation in a year is highest at 12:00, August 18 of summer (as shown in Fig. 3-7 and 3-8) and the lowest temperature appears on January 27 (as shown in Fig. 3-9 and 3-10). In Guangzhou, China, sun shading in summer should be the primary concern of building design. In this paper the optimized result at the period in summer with strongest solar radiation is taken as the basic model and the rotation angle of the sun visor is further optimized. simulation is made on the typical day in three seasons (the overheating season, undercooling season and transition season), specifically at 9:00, 12:00, 15:00 and 17:00 on August 18, January 27 and March 21.

\section{Automatic optimization}

This research is using Genetic algorithm to optimize the design [4].The optimization objective is to make the training hall indoor illumination in different seasons and different time in the previous acquisition of light comfort range (specifically 280Lx-980Lx), and tends to be the most comfortable value of $600 \mathrm{Lx}$, and adjust the indoor heat radiation level at the same time.

\section{Optimum design result}

\section{Optimization design result of training stadium designed with top and side-lighting}

1. Sunshade optimization design at 12:00 on August 18 in summer

(1)As shown in Table 3-1, the simulation calculation result of indoor light environment and solar radiation of space model 1 , space model 1 has relatively poor daylight uniformity, beyond the initially obtained scope of light comfort, high in solar radiation, characterized by poor indoor light environment and solar radiation. 
Table 3-1 Simulation calculation result of indoor light environment and solar radiation of space model $1^{1}$

\begin{tabular}{c|c|c|c|c|c}
\hline$E_{\text {ave }}(L x)$ & $E_{\max }(L x)$ & $E_{\min }(L x)$ & $\mathrm{U}_{1}$ & $\mathrm{U}_{2}$ & $\operatorname{Rad}(\mathrm{Wh})$ \\
\hline 14908 & 86202 & 4762 & 0.32 & 0.055 & 867 \\
\hline
\end{tabular}

2. Sunshade optimization design at 12:00 on August 18 in summer

(1) Space model 2 is subjected to optimization design, and the optimum solution is shown in Table 3-2.

Table 3-2 Optimum solution of optimization design

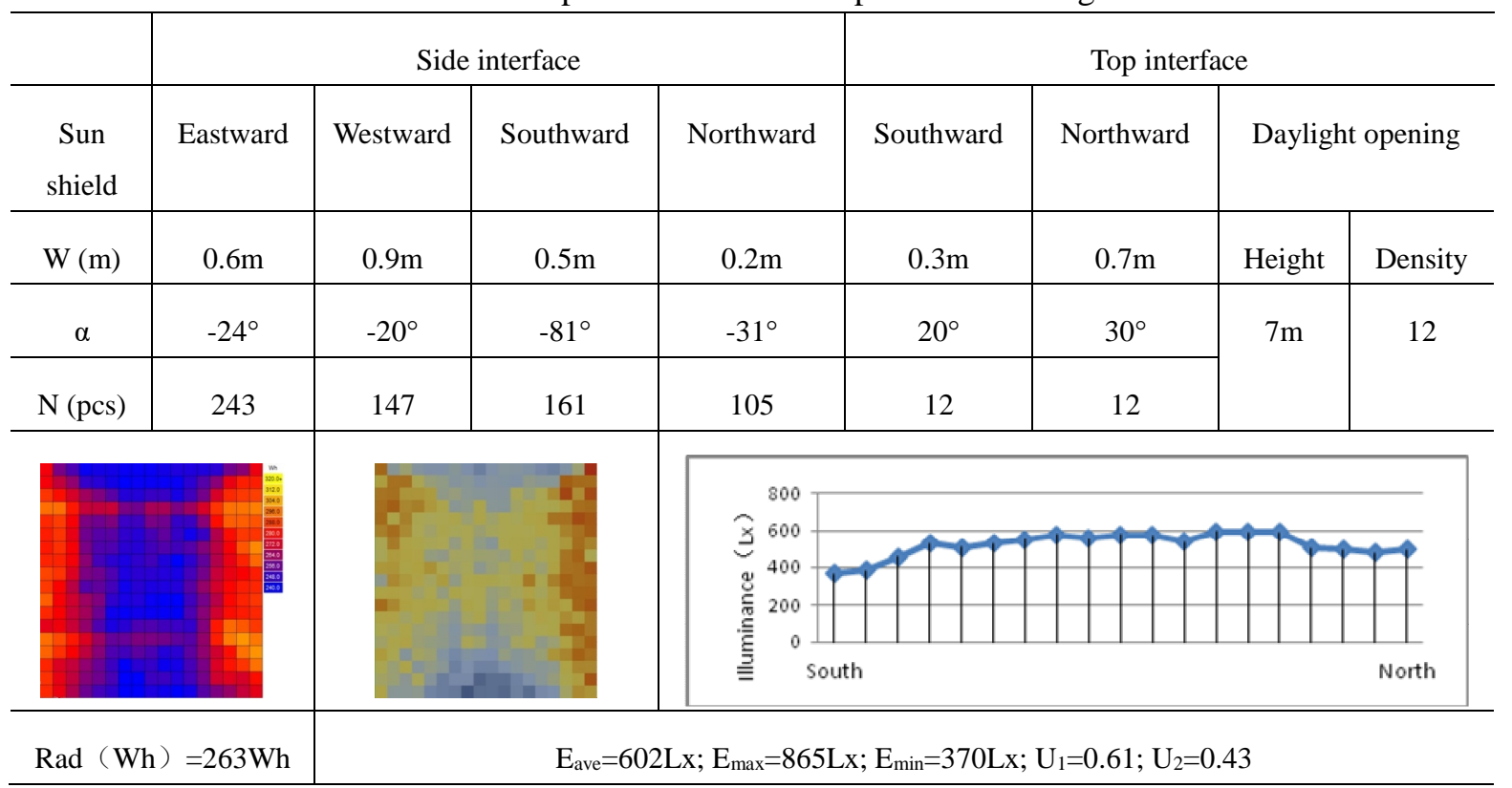

As shown in above table, optimization result has although balanced indoor illuminance, daylight uniformity and solar radiation to the greatest extent, is not the optimal result, since the uniformity has not yet complies with national regulation requirement.

(2)Based on the design result shown in Table 3-2, the rotation angle of sun shield on the top and side interface is in further optimized, in order to improve the indoor light uniformity and the comfort of indoor light environment. After optimization design, the optimum solution is provided in Table 3-3, and the optimization result has reached the target.

Table 3-3 Optimum solution of optimization design

\begin{tabular}{|c|c|c|c|c|c|c|}
\hline \multirow[b]{2}{*}{ Sun shield } & \multicolumn{4}{|c|}{ Side interface } & \multicolumn{2}{|c|}{ Top interface } \\
\hline & Eastwarc & Westward & Southward & Northward & Southward & Northward \\
\hline \multirow[t]{2}{*}{$\alpha$} & $-72^{\circ}$ & $-68^{\circ}$ & $-52^{\circ}$ & $-45^{\circ}$ & $-13^{\circ}$ & $-19^{\circ}$ \\
\hline & & 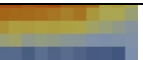 & \multicolumn{2}{|c|}{ South } & & North \\
\hline $\operatorname{Rad}(\mathrm{Wh})$ & Wh & Eave & $L x ; E_{\max }=53$ & $\mathrm{E}_{\min }=282 \mathrm{~L}$ & $=0.64 ; \mathrm{U}_{2}=0$. & \\
\hline
\end{tabular}

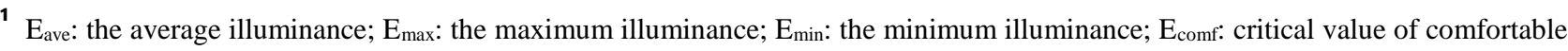
illuminance; $\mathrm{U}_{1}$ : the ratio of minimum illuminance to the average illuminance; $\mathrm{U}_{2}$ : the ratio of minimum illuminance to the maximum illuminance; Rad: solar radiation value.
} 
3. Optimization design result of space model 2

(1) Optimization design result on August 18 in summer (strongest illuminance)

(1) Simulation analysis optimum solution for indoor environment and solar radiation in different periods is shown in Table 3-4.

Table 3-4 Simulation analysis optimum solution for indoor environment and solar radiation in different periods

\begin{tabular}{c|c|c|c|c}
\hline & $9: 00$ & $12: 00$ & $15: 00$ & $17: 00$ \\
\hline$E_{\text {ave }}(\mathrm{Lx})$ & $582 \mathrm{Lx}$ & $441 \mathrm{Lx}$ & $585 \mathrm{Lx}$ & $537 \mathrm{Lx}$ \\
\hline $\mathrm{E}_{\max }(\mathrm{Lx})$ & $743 \mathrm{Lx}$ & $531 \mathrm{Lx}$ & $701 \mathrm{Lx}$ & $571 \mathrm{Lx}$ \\
\hline $\mathrm{E}_{\min }(\mathrm{Lx})$ & $420 \mathrm{Lx}$ & $282 \mathrm{Lx}$ & $477 \mathrm{Lx}$ & $367 \mathrm{Lx}$ \\
\hline $\mathrm{U}_{1}$ & 0.72 & 0.64 & 0.82 & 0.68 \\
\hline $\mathrm{U}_{2}$ & 0.57 & 0.53 & 0.68 & 0.52 \\
\hline $\mathrm{Rad}(\mathrm{Wh})$ & 162 & 234 & 173 & 40 \\
\hline
\end{tabular}

(2)The whole-day indoor illuminance of space model 1 and 3 is respectively shown in Fig. 3-1 and 3-2.

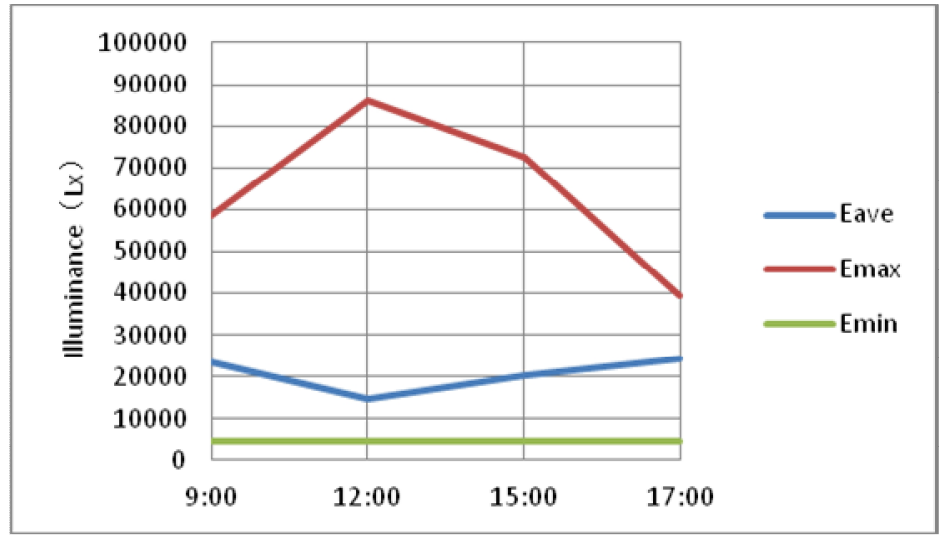

Fig. 3-1 Broken line graph for whole-day indoor illuminance of space model 1

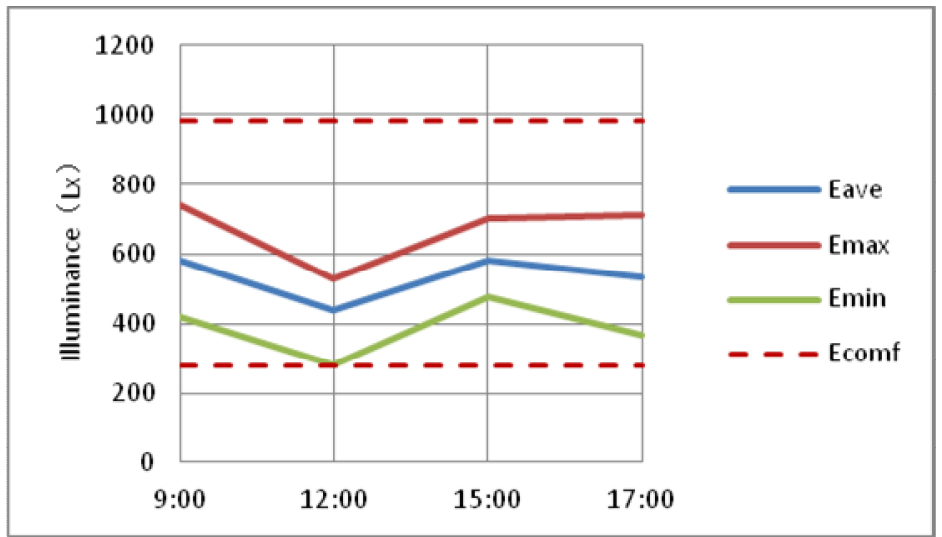

Fig. 3-2 Broken line graph for whole-day indoor illuminance of space model 2

(2) Optimization design result on January 27 in winter

(1) Simulation analysis optimum solution for indoor environment and solar radiation in different 
periods is shown in Table 3-5.

Table 3-5 Simulation analysis optimum solution for indoor environment and solar radiation in different periods

\begin{tabular}{c|c|c|c|c}
\hline & $9: 00$ & $12: 00$ & $15: 00$ & $17: 00$ \\
\hline$E_{a v e}(\mathrm{Lx})$ & $489 \mathrm{Lx}$ & $636 \mathrm{Lx}$ & $597 \mathrm{Lx}$ & $531 \mathrm{Lx}$ \\
\hline $\mathrm{E}_{\max }(\mathrm{Lx})$ & $661 \mathrm{Lx}$ & $838 \mathrm{Lx}$ & $766 \mathrm{Lx}$ & $801 \mathrm{Lx}$ \\
\hline $\mathrm{E}_{\min }(\mathrm{Lx})$ & $318 \mathrm{Lx}$ & $445 \mathrm{Lx}$ & $346 \mathrm{Lx}$ & $346 \mathrm{Lx}$ \\
\hline $\mathrm{U}_{1}$ & 0.65 & 0.70 & 0.73 & 0.65 \\
\hline $\mathrm{U}_{2}$ & 0.48 & 0.53 & 0.57 & 0.43 \\
\hline $\mathrm{Rad}(\mathrm{Wh})$ & 143 & 225 & 125 & 23 \\
\hline
\end{tabular}

(2)The whole-day indoor illuminance of space model 1 and 3 is respectively shown in Fig. 3-3 and $3-4$.

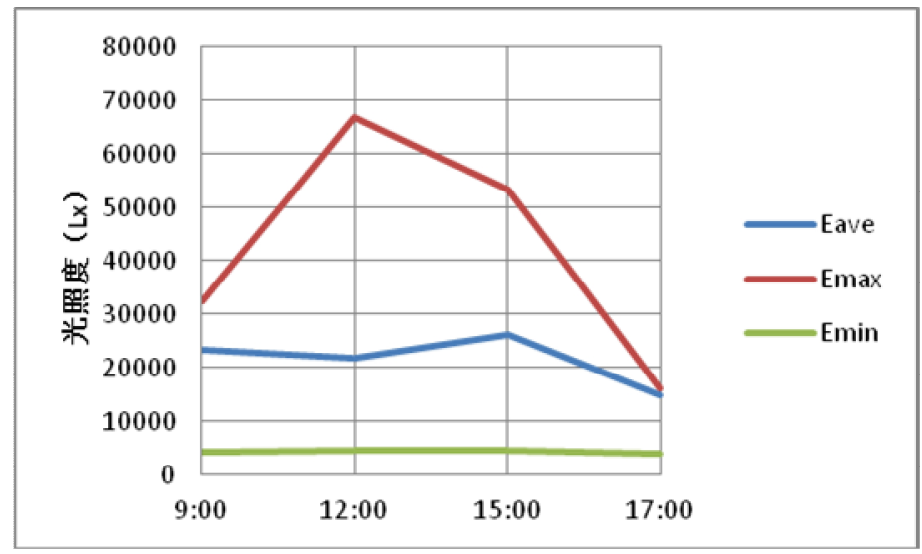

Fig. 3-3 Broken line graph for whole-day indoor illuminance of space model 1

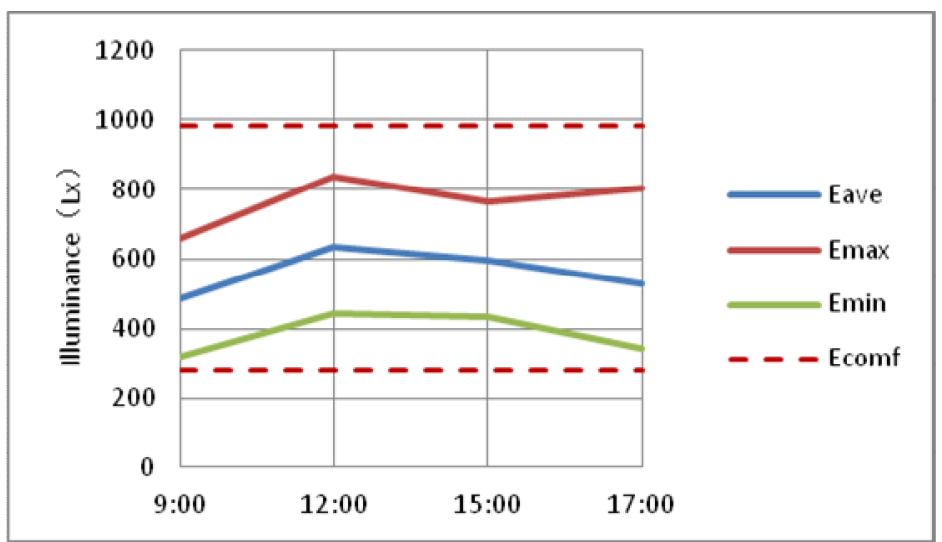

Fig. 3-4 Broken line graph for whole-day indoor illuminance of space model 2

(3) Optimization design result on March 21 in transition season

(1) Simulation analysis optimum solution for indoor environment and solar radiation in different periods is shown in Table 3-6. 
Table 3-6 Simulation analysis optimum solution for indoor environment and solar radiation in different periods

\begin{tabular}{c|c|c|c|c}
\hline & $9: 00$ & $12: 00$ & $15: 00$ & $17: 00$ \\
\hline$E_{\text {ave }}(\mathrm{Lx})$ & $706 \mathrm{Lx}$ & $675 \mathrm{Lx}$ & $631 \mathrm{Lx}$ & $569 \mathrm{Lx}$ \\
\hline $\mathrm{E}_{\max }(\mathrm{Lx})$ & $936 \mathrm{Lx}$ & $882 \mathrm{Lx}$ & $754 \mathrm{Lx}$ & $702 \mathrm{Lx}$ \\
\hline $\mathrm{E}_{\min }(\mathrm{Lx})$ & $464 \mathrm{Lx}$ & $489 \mathrm{Lx}$ & $469 \mathrm{Lx}$ & $421 \mathrm{Lx}$ \\
\hline $\mathrm{U}_{1}$ & 0.66 & 0.73 & 0.74 & 0.74 \\
\hline $\mathrm{U}_{2}$ & 0.50 & 0.55 & 0.62 & 0.60 \\
\hline $\operatorname{Rad}(\mathrm{Wh})$ & 59 & 88 & 54 & 16
\end{tabular}

(2) The whole-day indoor illuminance of space model 1 and 3 is respectively shown in Fig. 3-5 and 3-6.

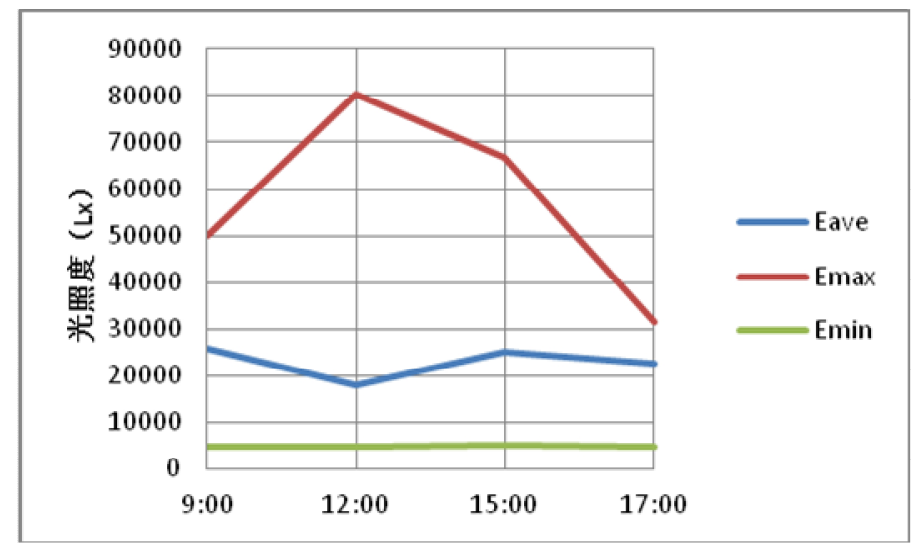

Fig. 3-5 Broken line graph for whole-day indoor illuminance of space model 1

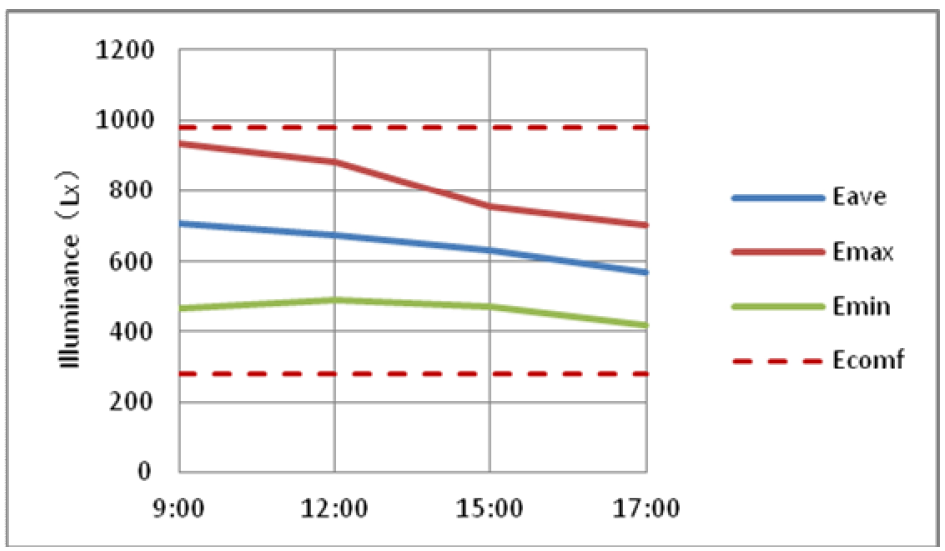

Fig. 3-6 Broken line graph for whole-day indoor illuminance of space model 2

As shown by the simulation analysis result of indoor light environment and solar radiation in each periods of each season, the space model 2 can, in each periods of each season, can reach the optimization objective by dynamically controlling the sun shield.

\section{Optimization design result analysis}

(1) Confirmation of optimal solution interval

Each variable value obtained by optimization at 12:00 in summer is imported to Excel, and with 
each variable value as the abscissa and the average illuminance within scope of comfort as the vertical coordinate, a scatter diagram is generated. Based on the distribution of scatter diagram, the optimal value taking interval for each variable can be obtained.

(2) Analysis of functional relationship between illuminance and solar radiation

After the average illuminance and solar radiation data obtained by optimization at 12:00 in summer is imported to Excel, a scatter diagram and fitted curve can be generated, as shown in Fig. 4-1:

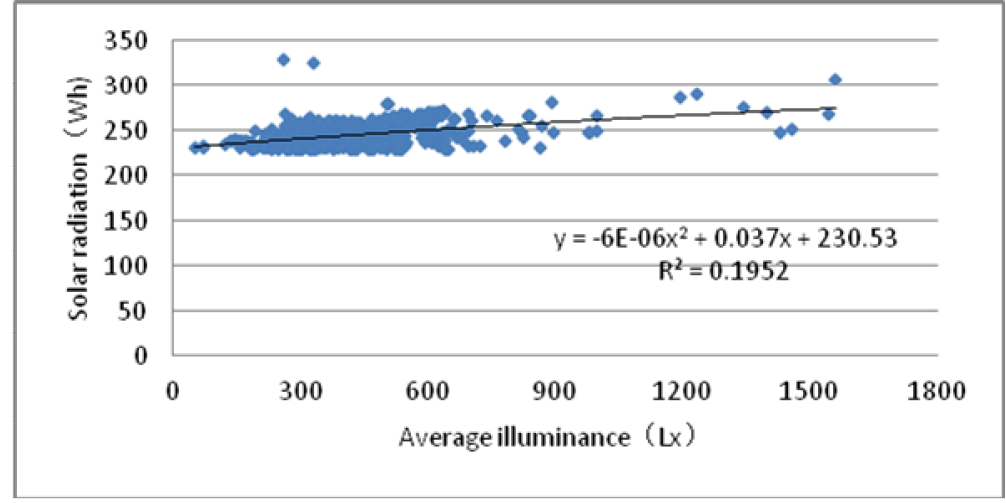

Fig. 4-1 Scatter diagram of average illuminance and solar radiation

A functional equation can be obtained from above scatter diagram:

$y=-6 E-06 x 2+0.037 x+230.5, R 2=0.195$.

\section{Conclusion}

The following conclusion is made during this research through optimization design:

At 12:00 in summer, for a training stadium designed with top and side-lighting, the function relationship between indoor illuminance and solar radiatio is: $\mathrm{y}=-6 \mathrm{E}-06 \mathrm{x} 2+0.037 \mathrm{x}+230.5, \mathrm{R} 2$ $=0.195$. According to predecessors, The comfort scope of indoor illuminance in training stadium in Guangzhou, China is 280Lx-980Lx, and the corresponding scope of indoor solar radiation is $240 \mathrm{Wh}-260 \mathrm{Wh}$, and therefore when the optimal comfort value of indoor illuminance is $600 \mathrm{Lx}$, the corresponding indoor solar radiation will be $250 \mathrm{Wh}$.

National Natural Science Foundation (number:51378210) Supported.

\section{References}

[1] Lv Ming, An Automatic Optimization External Shading Component Based on Solar Radiation [D]. Nanjing University, 2014.

[2] Shen Jie, Application of Green Building Technology Analysis Method Based on Grasshopper [D]. South China University of Technology, 2012. 
[3] Farhri B, John F, Robin D, Evolutionary Algorithms for Sustainable Building Design [C]. The $2^{\text {nd }}$ International Conference on Sustainable Architecture and Urban Development, Jordan, 2010:1-15.

[4] Gong Maoguo, Jiao Licheng, Yang Dongdong, et al, Research on Multi-Objective Evolutionary Algorithm [J], Journal of Software, 2009, 20 (2): 271-289. 